\title{
COMPARISON OF RESULTS OF SURGICALLY INDUCED ASTIGMATISM AND VISUAL ACUITY FOLLOWING TEMPORAL VERSUS SUPERIOR SCLEROCORNEAL INCISIONS IN MANUAL SMALL INCISION SUTURE LESS CATARACT SURGERY
}

H N Sowbhagya ${ }^{1}$, Kiran Kumar L², Kirthi Raj ${ }^{3}$, Pooja Patil ${ }^{4}$, Aisha Rafi5 ${ }^{5}$ Liji P6, Himamshu N V V77.

1. Professor, Department of Ophthalmology, Kempegowda Institute of Medical Sciences and Research Centre.

2. Assistant Professor, Department of Ophthalmology, Kempegowda Institute of Medical Sciences and Research Centre.

3. Post Graduate, Department of Ophthalmology, Kempegowda Institute of Medical Sciences and Research Centre.

4. Post Graduate, Department of Ophthalmology, Kempegowda Institute of Medical Sciences and Research Centre.

5. Post Graduate, Department of Ophthalmology, Kempegowda Institute of Medical Sciences and Research Centre.

6. Post Graduate, Department of Ophthalmology, Kempegowda Institute of Medical Sciences and Research Centre.

7. Professor and HOD, Department of Ophthalmology, Kempegowda Institute of Medical Sciences and Research Centre.

\section{CORRESPONDING AUTHOR:}

Dr H. N. Sowbhagya,

41-42/45, Sri Gurukrupa,

$7^{\text {th }}$ Cross, Saraswathipuram, Bangalore-96.

E-mail: drhnsowbhagyaappaji@gmail.com

\section{HOW TO CITE THIS ARTICLE:}

H.N. Sowbhagya, Kiran Kumar, Kirthi Raj, Pooja Patil, Aisha Rafi, Liji P, Himamshu N. V.V. "Comparison of Results of Surgically induced Astigmatism and visual acuity following temporal versus superior Sclerocorneal Incisions in manual small Incision Suture less Cataract Surgery". Journal of Evolution of Medical and Dental Sciences 2013; Vol2, Issue 23, June 10; Page: 4205-4217.

\section{ABSTRACT: OBJECTIVE:}

- To evaluate the effect of superior and temporal sclerocorneal incisions on astigmatism in small incision cataract surgery.

- To evaluate the success of different meridional approaches in cataract surgery by changing the sites of incision.

- To evaluate visual acuity outcomes on temporal versus superior sclerocorneal incisions.

DESIGN: Prospective, non-randomized, comparative clinical study.

PARTICIPANTS: One hundred and twenty eyes of 120 patients with cataracts scheduled to undergo routine cataract surgery. METHODS: 120 eyes of 120 patients were allocated to two groups of 60 each, Group TI (Temporal incision) and Group SI (Superior incision).Manual Small Incision sutureless Cataract Surgery was (MSICS) done. Post operative follow-up was done on day1, $2^{\text {nd }}, 4^{\text {th }}$ and $6^{\text {th }}$ weeks for post-operative clinical findings, visual acuity and keratometry. Data wasanalyzed by1] Descriptive and inferential statistical analysis.2] Mean \pm SD (Min-Max). 3] Student T test (Two tailed, independent).4] Chi-Square/Fisher Exact Test. RESULTS: The SIA (surgically induced astigmatism) vectors in the superior group showed a high coherence, implying a high predictive value of the centroid that is $1.11 \mathrm{D} \times 178$ degree. This indicates that making a superior incision consistently induced an average of 1.11D of horizontal steeping. The SIA vectors of the temporal 
group also showed high coherence implying a high predictive value and a temporal incision consistently induced an average horizontal flattening of about 0.48D. On the sixth post operative week visual acuity in TI group was $6 / 6$ to $6 / 9$ in $48(80 \%)$ patients, $6 / 12$ to $6 / 18$ in $10(16.7 \%$ ) patients and 6/24 to 6/36 in 2 (3\%) patients. In SI group visual acuity was 6/6 to 6/9 in 20(33.3\%), $6 / 12$ to $6 / 18$ in $34(56.7 \%)$ patients, $6 / 24$ to $6 / 36$ in $6(10 \%)$ patients and the difference is statistically significant $(\mathrm{P}<0.001)$.

The percentage of change in the best uncorrected visual acuity being $+80 \%(6 / 6-6 / 9)$ in TI group compared to $+33.3 \%$ in SI group. CONCLUSION: Less SIA and faster visual rehabilitation occurs in TI compared to SI in MSICS.

KEY WORDS: Manual small incision cataract surgery, surgically induced astigmatism, superior versus temporal sclerocorneal incisions.

INTRODUCTION: In The evolution of cataract surgery, manual small incision cataract surgery (MSICS) was a later addition much after phacoemulsification became a popular technique. It is neither a hi-tech procedure, nor is it practiced in Western countries. For that matter, MSICS was developed mainly as a cost-effective alternative to phacoemulsification ${ }^{1}$

Phacoemulsification (PE) is the preferred technique for cataract surgery in developed countries, and also to some extent in the developing countries. An alternative surgical technique, manual sutureless small incision extracapsular cataract surgery, has been gaining popularity, as the technique has been shown to yield comparable surgical outcomes as phacoemulsification. Both phacoemulsification and manual small incision cataract surgery (MSICS) achieve excellent visual outcomes with low complication rates, but MSICS is less expensive and requires less technology; hence, preferred by many surgeons in the developing countries ${ }^{2}$

MSICS can be done in immature, mature, and hypermature cataracts. It has also been done is cases of phacolytic glaucoma and can be combined with trabeculectomy surgeries. MSICS is safe in presence of corneal opacity in expert hands ${ }^{3}$.Venkatesh et al performed MSICS in white cataracts with the use of trypan blue as an adjunct for performing continuous curvilinear capsulorrhexis (CCC). They reported that MSICS is a safe and efficacious alternative for white cataracts especially with the adjunctive use of trypan blue dye. ${ }^{3}$

The scleral tunnel incision in cataract surgery was introduced in the early eighties in an attempt to provide better wound healing with less surgically induced astigmatism. The length of the incision varies from 5 to $8 \mathrm{~mm}$; however it is still called small incision cataract surgery since the architectural design renders sutureless, self sealing property to the incision. Girard and Hoffman ${ }^{4}$ were the pioneer to name this posterior incision as Scleral Tunnel Incision.

Ruitet al. compared the efficacy and visual results of phacoemulsification vs MSICS for the treatment of cataracts. They compared cases on parameters like operative time, surgical complications, uncorrected visual acuity (UCVA), BCVA, astigmatism, and central corneal thickness (CCT). They found that both the surgical techniques achieved excellent surgical outcomes with low complication rates. At six months, $89 \%$ of the MSICS patients had UCVA of 20/60 or better and $98 \%$ had a BCVA of $20 / 60$ or better vs $85 \%$ of patients with UCVA of $20 / 60$ or better and $98 \%$ of patients with BCVA of $20 / 60$ or better at six months in the phaco group $(P=0.30)$. Surgical time for MSICS was much shorter than that for phacoemulsification $(\mathrm{P}<.0001)$. They concluded that MSICS 
is a more appropriate surgical procedure for the treatment of advanced cataracts in the developing world 5 .

Wound construction plays a major role in MSICS, which may be more important than its role in phacoemulsification, where the size and shape and type of the wound remain same in most of the cases. The properties of a reliable self-sealing incision are:

1. Square incisional geometry.

2. Relatively short external incision with a tunnel that flares to a larger internal incision.

3. Geometric external incision shape that lends itself to stretching6, 7 .

Construction of a small, self-sealing sclerocorneal tunnel for delivering the cataractous lens is the central principle in MSICS and the procedure can be done with either a temporal or a superior incision, whichever is more convenient. The temporal site is best suited for deep sockets where the maneuverability through the superior site would be difficult.

The instruments that are required for construction of the sclerocorneal tunnel are 1) Westcott scissors, 2) cautery, 3) Bard-Parker knife with \#15 blade, 4) Castroviejo calipers, 5) crescent blade and 6) 45-degree-angled, 3.2-mm microkeratome. 7) Enlarger

The tunnel has six aspects: size (i.e., the length of the tunnel), shape (style), location, depth, width and entry place into the anterior chamber. ${ }^{8}$

The width of the tunnel is the distance between the external scleral incision and the internal corneal entry incision, which should be at least $4 \mathrm{~mm}$ in size. The external configuration may either be straight or curved. Gokhaleet al, compared the induced astigmatism with various positions of scleral incision (superior, supero-temporal and temporal incision) in MSICS. The study found that surgery induced astigmatism was lower in the temporal and superotemporal groups compared to that in the superior group. ${ }^{9}$

Parmaret al compared the per-operative contamination of anterior chamber among eyes undergoing MSICS and phacoemulsification. They studied 150 eyes undergoing cataract surgery. Aqueous samples were taken before and at the end of surgery. Collected material was subjected to standard microbiological analysis. No preoperative antibiotics were used, but povidone-iodine 5\% drops were instilled before surgery. They found that the incidence of anterior chamber contamination in the MSICS group (4\%) did not differ significantly ( $\mathrm{P}=0.65$ ) from the PE group (2.7\%; $\mathrm{P}=0.65)$. Hence MSICS is an accepted, safe and economical cataract surgery procedure ${ }^{10}$.

MATERIAL AND METHODS: The study was conducted as a prospective Randomised study including patients visiting the Ophthalmology Department of a teaching hospital in Bangalore between Aug 2010 to Feb 2012 after obtaining ethical committee clearance.

INCLUSION CRITERIA:1) Presence of cataract and subject's willingness for surgery. 2) Healthy limbus and peripheral cornea. 3) Age between 19 and above of either sex and patients who could be available for follow up.

EXCLUSION CRITERIA:1) Patients with high corneal irregularities greater than two diopters of astigmatism.2) Patients with complicated cataract.3) Patients with pre-existing corneal opacity, degeneration, dystrophies, uveitis or glaucoma.4) Patients with ocular surface disorders.5).Patients with obvious posterior segment pathologies.6) Pre-existing corneal ectasia.7) Systemic illness like thyroid pathology, collagen disorders and pregnancy which could alter corneal hysteresis.8) Fragile 
subjects and patients with physical disabilities who cannot co-operate for repeated keratometry.9) Scleral pathology Patients who presented for elective cataract surgery were evaluated as per inclusion and exclusion criteria mentioned above. A total of 120 patients were studied who had uneventful surgery and completed follow-up. The surgical procedure is a manual small incision cataract surgery (MSICS) with posterior chamber intraocular lens implantation being performed under local anaesthesia and were allocated to two groups of 60 each, Group1: Temporal incision (TI) and Group2: Superior incision (SI). Descriptive statistics was used to express values of parameters as mean and Standard Deviation and for the purpose of comparison of mean values of parameters Student's t- test (Two tailed) was used and the associations were studied using ChiSquare/Fisher Exact Test. Any p value less than or equal to 0.05 was considered to be statistically significant.

PRE-OPERATIVE ASSESSMENT: After obtaining Institutional ethical committee an informed consent was obtained in every case. Study is done according to the WMA Declaration of Helsinki and guidelines of ICMR. Detailed history recorded. General systemic examination and ocular examination was done to fulfill the inclusion criteria and exclusion criteria. Biomicroscopic examination of the anterior segment was done. Lens opacity graded according to LOCS classification. The visual acuity was recorded for both distance and near with/without correction. The IOP was recorded by "I care" (rebound tonometry). A gonioscopic evaluation, fundus examination was done by direct and indirect ophthalmoscope. Lacrimal syringing was done to assess the patency of the lacrimal passages. Ultrasound B scans for patients with opaque media to evaluate posterior segment. Keratometry readings were recorded using Huvitz automated keratometer (HRK-7000) and A-scan biometry (using-OTI-SCAN 1000), IOL power was calculated as per SRK-2 formula. K-reading was recorded as K1 (refractive power of minimum meridian) and K2 (refractive power of maximum meridian). The amount and type of pre-operative astigmatism was noted in all patients. Xylocaine test dose was given to all cases one day prior to the surgery. All cases received topical antibiotics (Moxifloxacin 0.5\%) eye drops 6th hourly one day prior to surgery and eyelashes were trimmed, tropicamide (0.08\%), phenylephrine (5\%) combination and topical flurbiprofen $(0.03 \%)$ every 15 minutes instilled in the operating eye an hour before surgery.

SURGICAL TECHNIQUE: All the patients were operated according to the generally accepted principles of cataract surgery. Eyelids, periorbital area was painted with betadine (5\%). Peribulbar block was given with combined 2\% lignocaine, $1: 1000$ adrenaline and hyaluronidase $(7.5 \mathrm{IU} / \mathrm{ml})$. Draping of operating eye was done and wire speculum used to retract eye lids.

SUPERIOR SCLERAL STRAIGHT INCISION SICS: (fig-1) Surgeon seated at head end of the patient, superior rectus bridle suture was put, fornix based conjunctival flap was taken between 2 o'clock and $10 o^{\prime}$ clock down to bare sclera, bleeding points were cauterized. A straight scleral incision of about $6.5 \mathrm{~mm}$ was placed $1.5 \mathrm{~mm}$ behind the limbus using 15 No. BP blade. Sclero-corneal tunnel was done with beveled up crescent blade up to $2 \mathrm{~mm}$ inside the clear cornea. Side port was made at 9 o'clock position and anterior capsule was stained with tryphan blue. Anterior chamber filled with viscoelastic, continuous curvilinear capsulorrhexis was done through the side port. Anterior chamber entry was done through the main port using $3.2 \mathrm{~mm}$ keratome and incision was extended laterally using enlarger. The internal opening made was 11-12 mm. Hydrodissection was done 
using 30 gauge cannula and nucleus was prolapsed into the anterior chamber. Delivery of the nucleus was done with sandwich technique using corrugated vectis and Sinskey hook. Anterior chamber depth was maintained with viscoelastic. After delivering the nucleus, remaining cortex was aspirated using Simcoe Irrigation\& Aspiration cannula, 12 o' clock cortical clean up done through side port. Posterior chamber PMMA single piece lens of $6 \mathrm{~mm}$ optic diameter (overall 12.5 $\mathrm{mm}$ ) was implanted in the bag. Anterior chamber cleared of remaining viscoelastic and reformed with balanced salt solution, side-port hydrated. Main wound was checked for any leakage, subconjunctival injection of dexamethasone $4 \mathrm{mg}$ and gentamycin $20 \mathrm{mg}$ was given and eye was patched. All the above procedures were uneventful. Difficulties faced were 1) nose bridge and brow hinderance while operating left eyes. 2) Brow obstruction while operating in deep set eyes.

TEMPORAL SCLERAL STRAIGHT incision MSICS: (fig-2) It does not differ much from superior incision but needs some modification of surgeons procedures. The surgeon needs to sit on the temporal side of the eye to be operated and corresponding shift of operating microscope. Fornix based conjunctival flap was taken from 10 o'clock to $8 o^{\prime}$ clock, $6.5 \mathrm{~mm}$ scleral straight incision was placed around 1-1.5mm posterior to limbus and side port was made around 1 to 2 clock hours away from the main port at 6-o clock position for right eyes and superior 12 o clock hour for the left eyes. Rest of the steps used in this procedure was similar to the superior incision group.Minor intraoperative complications like iris prolapse, difficulty in delivering the nucleus and premature entry and button holing etc were managed accordingly. Any case requiring the suturing of the wound or side port and button holed cases were excluded from the study.

POST OPERATIVE WORK UP: All patients were put on topical prednisolone acetate (1\%) and moxifloxacin $(0.5 \%)$ and flurbiprofen $(0.03 \%)$ for total 6 weeks. Post operative follow-up done on day $1,2^{\text {nd }}, 4^{\text {th }}$ and $6^{\text {th }}$ weeks for postoperative clinical findings, visual acuity and keratometry readings. Results were analysed. Keratometry values in two perpendicular meridians were recorded pre-operative and post-operative on every follow up visits using Huvitz auto ref/keratometer.WTR and ATR of specific amount were then deduced from these readings for every case of each visit. Cases with 70 degrees to 110 degrees axis were considered as WTR astigmatism and cases with 160 degrees to 20 degrees axis were considered as ATR astigmatism. Other axis was excluded from the study. Preoperative and post operative ( $6^{\text {th }}$ week) Keratometric readings were used for analysis. All calculations were performed using surgically induced astigmatism (SIA) Calculator Version 2.1 a free software programme. Amplitude of preoperative and postoperative astigmatism was calculated from the difference in keratometric value in the steeper and flatter meridian, using the plus cylinder notation. Astigmatism was considered a vector with a magnitude equal to this value directed towards the steeper meridian. For example, keratometry values of 43.5 $\mathrm{x} 90^{\circ}$ and $44 \times 180^{\circ}$ would imply astigmatism of $0.5 \mathrm{D} 180^{\circ}$. The amplitude of SIA was also calculated for each eye from the preoperative and postoperative amplitudes using the SIA software programme.

The data was also analyzed using Cartesian Coordinates based analysis with Holladay's system whereby each of the astigmatic vectors were converted into $\mathrm{x}$ and $\mathrm{y}$ values. These $\mathrm{x}$ and $\mathrm{y}$ values were independently averaged and reconverted into the astigmatic vector form, producing mean pre and post-operative astigmatic values for the group. This mean astigmatism called the centroid represents the true mean of the data set, which takes into consideration all the elements 
forming the data. From the pre and post-operative $\mathrm{x}$ and $\mathrm{y}$ values, SIA $\mathrm{x}$ and $\mathrm{y}$ values were also calculated for each eye. These were averaged and converted into vector form which gives the SIA centroid.

RESULTS: In this prospective, non-randomised comparative study done in two groups with 60 patients in each to assess the surgically induced corneal astigmatism. (Table 1)The comparison of mean age of the two groups showed no statistical significance (p-0.158),Out of the total 120 patients, 54(45\%) were male and 66(55\%)were females with no significant differences among their distribution in two groups ( $\mathrm{p}=0.604)$ (Table 2) Eye involved: Among 120 patients, 62 patients $(51.7 \%)$ got operated in left eye while 58 patients (48.3\%) were operated on the right eye and is statistically similar with $(\mathrm{p}=1.00)$ (Table 3).The distribution of the different types of cataract in total was 70\% SIMC (immature), $28.3 \%$ mature and $1.7 \%$ posterior sub capsular. Pre-operative visual acuity ranged from majority with only CF (1-3mts) $41.7 \%$ to a minimum of $6.7 \%$ HMCF. Others had $6 / 60$ or less $(36.7 \%)$ and PL +ve(15\%). Thus there was no significant difference between the two groups $(\mathrm{p}=0.39)$ (Table 4).In the present study, in temporal incision group $20(33.3 \%)$ had WTR astigmatism, 36(60.0\%) had ATR astigmatism and no astigmatism in 4(6.7\%). In superior incision group 30(50.0\%) had WTR astigmatism, 26(43.3\%) had ATR astigmatism and $4(6.7 \%)$ had no astigmatism hence pre-op astigmatism was similar in two groups and there was no statistical significance ( $\mathrm{p}=0.43$ ) (Table 5).In the present study, 20 patients in temporal group and 30 patients in superior group had WTR astigmatism pre-operatively with a mean astigmatism $0.8 \pm 0.63$ and $0.98 \pm 0.49$ respectively, the difference not significant statistically $(\mathrm{p}=0.425$ ) (Table6).On the $1^{\text {st }}$ post-operative day, mean astigmatism in TI group was $1.38 \pm 0.96$ and in the SI group $2.25 \pm 0.83$. The change has been found to be significant $\mathrm{P}=0.023$. On the $2^{\text {nd }}$ post-operative week, mean astigmatism in TI group was $1.25 \pm 0.78$ and SI group was $1.40 \pm 0.65$. Hence the difference was statistically not significant $(\mathrm{P}=0.617)$.On the $4^{\text {th }}$ post-operative week, mean astigmatism in $\mathrm{TI}$ group was $1.35 \pm 0.94$ and SI group was $1.00 \pm 0.59$. Hence no significant difference between the group $(\mathrm{P}=0.302)$. On the $6^{\text {th }}$ post-operative week, mean astigmatism in TI group was $1.11 \pm 0.88$ and $\mathrm{SI}$ group was $0.65 \pm 0.68$. Hence no significant difference noted in both the group $(\mathrm{P}=0.163)$. There was a decrease in amount of mean astigmatism in SI group, whereas in TI group there was increase in amount of astigmatism at the end of six weeks. In the present study 36 patients in TI group and 24 patients in SI group had ATR astigmatism pre-operatively with a mean astigmatism $0.75 \pm 0.38$ and $0.77 \pm 0.31$ respectively, the difference not significant statistically $(\mathrm{p}=0.881)$.0n the $1^{\text {st }}$ postoperative day, mean astigmatism in TI group was $1.09 \pm 0.91$ and in the SI group $1.92 \pm 0.75$. The change has been found to be significant $\mathrm{P}=0.012$.0n the $2^{\text {nd }}$ post-operative week, mean astigmatism in TI group was $0.75 \pm 0.74$ and SI group was $1.07 \pm 0.44$. Hence no significant difference between the groups $(\mathrm{P}=0.170) .0 n$ the $4^{\text {th }}$ post-operative week, mean astigmatism in TI group was $0.43 \pm$ 0.39 and SI group was $1.50 \pm 0.69$. The change has been found to be significant $\mathrm{P}<0.001 .0 n$ the $6^{\text {th }}$ post-operative week, mean astigmatism in TI group was $0.38 \pm 0.3$ and SI group was $1.83 \pm 0.72$. The change has been found to be significant $\mathrm{P}<0.001$.There was decrease in amount of mean astigmatism in TI group where as there was increase in amount of mean astigmatism in SI group at the end of 6 weeks (Table 7).In the present study, pre-operatively in the TI group 20(33.3\%) had WTR astigmatism, 36(60\%) ATR and 4(6.7\%) had no astigmatism. In the SI group 30(50\%) had WTR astigmatism, 26(43.3\%) ATR and $4(6.7 \%)$ had no astigmatism. Hence the difference was statistically not significant $(\mathrm{P}=0.432)$ (Table8)In the present study mean calculated SIA in TI group 
was $0.77 \pm 0.54$ and in SI group the mean calculated SIA was $1.38 \pm 0.51$. The change has been found to be significant $\mathrm{P}<0.001$ (Table 9)The amplitude of pre-operative astigmatism was similar and around $0.72 \pm 0.50$ in TI group, $0.83 \pm 0.46$ in SI group. Hence the difference between the two group was not significant $\mathrm{P}=0.388$.The amplitude of post-operative astigmatism (6 $6^{\text {th }}$ week) was higher in SI group $(1.44 \pm 0.43)$ than in the TI group $(0.87 \pm 0.64)$. The change has been found to be sign (Table 10).

Analysis of the SIA centroid shows that 1.11D at 178 degree axes of horizontal steeping (or vertical flattening) was induced by making a superior incision whereas the temporal incision induced a average horizontal flattening (or vertical steeping) of about $0.48 \mathrm{D}$ at 86 degrees. The SIA vectors in the superior group showed a high coherence, implying a high predictive value of the centroid that is $1.11 \mathrm{D} \times 178$ degree. This indicates that making a superior incision consistently induced an average of 1.11D of horizontal steeping. The SIA vectors of the temporal group also showed high coherence implying a high predictive value and a temporal incision consistently induced an average horizontal flattening of about 0.48D.(Table 11)In the present study, on the first post operative day visual acuity among 60 patients in TI group, 14(23.3\%) had visual acuity between $6 / 12$ to $6 / 18,18(30 \%)$ patients had visual acuity between $6 / 24$ to $6 / 36,26(43.4 \%$ ) had visual acuity of $6 / 60$ or less and $2(3.3 \%)$ had visual acuity between CF (1-3mts). In the SI group, $2(3.3 \%)$ had visual acuity between $6 / 6$ to $6 / 9,4(6.7 \%)$ had visual acuity between $6 / 12$ to $6 / 18$, $18(30 \%)$ had visual acuity between $6 / 24$ to $6 / 36,28(46.7 \%)$ had visual acuity of $6 / 60$ or less and $8(13.3 \%)$ had visual acuity between CF (1-3mts). Hence the difference between the two groups was found not to be significant $\mathrm{P}=0.223$ (Table 12).The reduced visual acuity on the first day $(\leq 6 / 36)$ is due to anterior chamber reaction and greater amount of SIA. On the second post operative week, visual acuity in TI group was $6 / 6$ to $6 / 9$ in $8(13.3 \%)$ patients, $6 / 12$ to $6 / 18$ in $30(50 \%)$ patients, $6 / 24$ to $6 / 36$ in $16(26.7 \%)$ and $6 / 60$ or less in $6(10 \%)$ patients. In SI group visual acuity was $6 / 6$ to $6 / 9$ in $4(6.7 \%), 6 / 12$ to $6 / 18$ in $18(30 \%)$ patients, $6 / 24$ to $6 / 36$ in $28(46.7 \%)$ patients and $6 / 60$ or less in $10(16.7 \%)$ patients. The difference was not statistically significant $(\mathrm{P}=0.237) .0 n$ the fourth post operative week, visual acuity in TI group was $6 / 6$ to $6 / 9$ in $40(66.7 \%$ ) patients, $6 / 12$ to $6 / 18$ in $14(23.3 \%$ ) patients, $6 / 24$ to $6 / 36$ in $6(10 \%)$. In SI group visual acuity was $6 / 6$ to $6 / 9$ in $10(16.7 \%), 6 / 12$ to $6 / 18$ in $32(53.3 \%)$ patients, $6 / 24$ to $6 / 36$ in $12(20 \%)$ patients and $6 / 60$ or less in $6(10 \%)$ patients. The improvement in visual acuity in the temporal group is better than the SI group, and the difference is statistically significant $(\mathrm{P}<0.001)$.The early improvement in visual acuity in TI is due to early stabilization of the astigmatism and better wound healing as compared to the SI. On the sixth post-operative week visual acuity in TI group was $6 / 6$ to $6 / 9$ in $48(80 \%)$ patients, $6 / 12$ to $6 / 18$ in $10(16.7 \%)$ patients and $6 / 24$ to $6 / 36$ in $2(3 \%)$ patients.In SI group visual acuity was $6 / 6$ to $6 / 9$ in $20(33.3 \%), 6 / 12$ to $6 / 18$ in $34(56.7 \%$ ) patients, $6 / 24$ to $6 / 36$ in $6(10 \%)$ patients and the difference is statistically significant $(\mathrm{P}<0.001)$.The percentage of change in the best uncorrected visual acuity being $+80 \%(6 / 6-6 / 9)$ in TI group compared to $+33.3 \%$ in SI group.

DISCUSSION: All patients underwent manual MSICS with PCIOL. 60 cases were allocated for superior incision and another 60 cases were allocated to temporal incision without considering the pre-operative astigmatism. Corneal astigmatism derived from keratometry readings have been found to correlate well with post-operative astigmatic refractive error according to the study by Maltzman ${ }^{11}$.Keratometry values in two perpendicular meridians were recorded pre-operative and post-operative on every follow up visits on 1st day, 2nd week, 4th week and 6th week using Huvitz 
auto ref/keratometer. Surgically induced astigmatism calculated by SIA 2.0 software using vector analysis and Cartesian co-ordinates with pre-operative and post-operative (6th week) Keratometric readings were used for analysis. WTR and ATR of specific amount were then deduced from these readings for every case of each visit. Among 120 patients, preoperatively 50(41.6\%) had WTR astigmatism, 62(51.6\%) had ATR astigmatism and 8(6.6\%) had no astigmatism. In comparison, the study by Vaithianathan ${ }^{12}$ of 147 cases showed pre-operative predominance of ATR with 109 cases and 38 cases with WTR. In the present study, the mean SIA in TI group was $0.77 \pm 0.54$ and in SI group it was $1.38 \pm 0.51$, the difference was found to be statistically significant $(\mathrm{P}<0.001)$. Similar study done by Gokhale N.S and Sawhney S (2005) ${ }^{13}$, the mean SIA in superior group was $1.36 \pm 1.03$ and in temporal group it was $0.40 \pm 0.40$.In the present study there was significant difference in the amount of astigmatism TI $(1.17 \pm 0.90)$, SI $(2.12 \pm 0.78)$ on the 1st post-operative day. However the astigmatism gradually reduced in both the groups and on the 4th post-operative week there was a reduction in the amount of astigmatism in both the groups, TI (0.59 \pm 0.63$)$, SI ( $1.20 \pm 0.88)$ and the differences was statistically significant $(\mathrm{p}<0.001)$. Similarly Brown SM, Hodges MR, Corona J $(2001)^{14}$ studied the relaxation of a $6.25 \mathrm{~mm}$ scleral wound after cataract surgery and found SIA to decay from 6.71D (day 1-15), 2.71D (day 15-30) and 1.93D (day 31-45); also comparable with studies conducted at Department of Ophthalmology, Kushimoto rehabilitation center, Japan ${ }^{15}$ and Edward S Markness Eye Institution College of Physicians and Surgeon, Columbia University, New York $^{16}$. In patients subjected to temporal scleral incision with pre-operative astigmatism, 20(33.3\%) had WTR astigmatism, 36(60\%) had ATR astigmatism and no astigmatism in 4(6.7\%) patients. At the 6th week post-operative had shifted to WTR astigmatism $40(66.7 \%)$, ATR astigmatism $16(26.7 \%)$ and no astigmatism $4(6.7 \%)$. The percentage of change is $+33.3 \%$ in WTR astigmatism. In patients subjected to superior scleral incision with pre-operative astigmatism, WTR astigmatism 30 patients (50\%), ATR 26 patients (43.3\%) and no astigmatism 4 patients (6.7\%). At the 6th post-operative week had shifted to 8 WTR (13.3\%), 42 ATR (70\%), and 10 with no astigmatism $(16.7 \%)$. The percentage of change is $+26.7 \%$ in ATR astigmatism.

Similarly, in a study by Zheng H, Merriam J.C, Zaider M17WTR astigmatism was seen to shift to ATR after $6 \mathrm{~mm}$ superior linear incision and stabilized over 1.2 months. Mean SIA centroid in TI group was 0.48 x 86 and SI group was 1.11 x 178 which was similar to study done by Gokhale N.S and Sawhney S (2005) ${ }^{13}$.In the present study, visual acuity on the first day was almost similar $(6 / 60$ or less) $43.3 \%$ in the TI group and $46.7 \%$ in SI group, this could be attributed to high astigmatism and in some anterior chamber reaction. In the 6th week post-operative follow up $48(80 \%)$ in TI group had visual acuity of $6 / 6$ to $6 / 9$ and 20 (33.3\%) in the SI group had 6/6 to 6/9 visual acuity. The results are consistent with previous reports that temporal incision induces small amount of WTR astigmatism and gives early visual rehabilitation to the patients within 6 weeks.

CONCLUSION: Post-operative astigmatism induced by surgery varied significantly with the location of the incision used in MSICS. Our results showed that a superior incision induces higher magnitude of ATR astigmatism, while the temporal incision induces lower magnitude WTR astigmatism. The temporal scleral incision is to be preferred in patients with pre-operative ATR astigmatism. 1) It is common in older age. 2) Early and better uncorrected visual acuity in the temporal sclerocorneal incision.

Pre-operative corneal astigmatism has a considerable role in the final refractive state of the patient and hence it would be extremely useful to plan the surgery based on pre-operative 
astigmatic reading in order to avoid worsening. In some cases study proves that changing the position of incision during cataract surgery can be of surgeon's choice. Superior incision is the usual site for all surgeries except in some superior limbal conditions like: 1) Past anti-glaucoma surgeries. 2) Limbal scars etc. Temporal incision showed added benefits, can be of choice for all the cases when pre-operative astigmatism is not high because: 1)TI stabilized early. 2) Induced less SIA, TI group was $0.77 \pm 0.54$ compared to SI group it was $1.38 \pm 0.51$ which is significant. 3)TI is more comfortable and surgeon friendly in deep set eyes and prominent eye brows more so for the left eyes.4)TI patients will not complain of post-operative discomfort like foreign body sensation or discomfort as wound will not be rubbed by the eyelids which are one of the post-operative morbidity. 5) Superior rectus bridle suture is not required; patient's agony of bridle suture and occulo-cardiac reflexes fear is avoided

\section{BIBLIOGRAPHY:}

1. Haldipurkar S S, Shikari HT, Gokhale V. Wound construction in manual small incision cataract surgery. Indian J Ophthalmol [serial online] 2009 [cited 2013 Mar 23]; 57:9-13.

2. Indian J Ophthalmol. 2009 Jan-Feb; 57(1): 79-82. Small incision cataract surgery: Review of Journal abstracts. Rajesh Sinha, Prakashchand Agarwal and Chandrashekhar Kumar.

3. Venkateshet al. (Indian J Ophthalmol. 2005; 53(3):173-6

4. Girard and Hoffman (Am J Ophthalmol 1984; 97:450-56)

5. Ruitet al. (Am J Ophthalmol. 2007; 143(1):32-38)

6. Gautam AK, Nath R, Kumar D, Saxena S. Early re-establishment of blood aqueous barrier after Phacoemulsification. Indian J Ophthalmol.1998; 46:173-4.[PubMed]

7. Pallin SL. Self-sealing incision. In Phacoemulsification. Agarwal S, Bonnett R, Agarwal A, editors. London: Taylor and Francis; 2004. pp. 199-204.

8. Haldipurkar, S. S. et al. Indian J Ophthalmol 2009; 57(1):9-13.0phthalmology.2000Nov; 107(11):2049-53.

9. Gokhaleet al. (Indian J Ophthalmol. 2005; 53(3):201-3)

10. Parmaret al (Am J Ophthalmol. 2006; 141(6):1160-1)

11. Maltzman BA, Cinnotti DJ, Horan CA, Rengel AM. Posterior chamber implants and post operative refractive astigmatism. CLAO J 1983; 9:229-31

12. Vaithianathan V, Kumar AM, Subalakshmi. Target emmetropia .All India Conf;2007

13. Gokhale NS, Sawhney S. Reduction in astigmatism in manual small incision cataract Surgery through change of incision site. Indian J Ophthalmol 2005; 53:201-3.

14. Brown SM, Hodges HR, Corona J. Relaxation of post op astigmatism in $6.25 \mathrm{~mm}$ scleral wound in children. J Cat \& Ref Surg 2001; 27(12): 2012-6.

15. Akura J, Kaneda S, Hatta S, Matsuara K, Controlling Astigmatism in cataract surgery Requiring relatively large self healing incisions. J Cataract Refract Surg .2000; 26:1650-59.

16. Zheng L, Merriam JC and Zaider M. Astigmatism and visual recovery after "large incision" extracapsular cataract surgery and "small" incisions for phacoemulsification. Tr Am OphthSoc 1997; XCV: 387-413.

17. Zheng L, Merriam JC and Zaider M. Astigmatism and visual recovery after "large incision" extracapsular cataract surgery and "small" incisions for phacoemulsification. Tr Am Ophth Soc 1997; XCV: 387-413(1997). 


\section{ORIGINAL ARTICLE}

Table 1: Age distribution

\begin{tabular}{|l|l|l|l|l|l|l|}
\hline \multirow{2}{*}{ Age in years } & \multicolumn{2}{l|}{ Temporal incision } & \multicolumn{2}{l|}{ Superior incision } & \multicolumn{2}{l|}{ Total } \\
\cline { 2 - 7 } & No & \% & No & \% & No & \% \\
\hline $40-50$ & 8 & 13.3 & 14 & 23.3 & 22 & 18.3 \\
\hline $51-60$ & 26 & 43.3 & 30 & 50.0 & 56 & 46.7 \\
\hline $61-70$ & 14 & 23.3 & 12 & 20.0 & 26 & 21.7 \\
\hline$>70$ & 12 & 20.0 & 4 & 6.7 & 16 & 13.3 \\
\hline Total & 60 & 100.0 & 60 & 100.0 & 120 & 100.0 \\
\hline Mean \pm SD & $60.88 \pm 10.04$ & $57.36 \pm 8.86$ & $59.12 \pm 9.56$ \\
\hline
\end{tabular}

Table 2: Sex Distribution

\begin{tabular}{|l|l|l|l|l|l|l|}
\hline \multirow{2}{*}{ Gender } & \multicolumn{2}{|l|}{ Temporal incision } & \multicolumn{2}{l|}{ Superior incision } & \multicolumn{2}{l|}{ Total } \\
\cline { 2 - 7 } & No & \% & No & \% & No & \% \\
\hline Male & 24 & 40.0 & 30 & 50.0 & 54 & 45.0 \\
\hline Female & 36 & 60.0 & 30 & 50.0 & 66 & 55.0 \\
\hline Total & 60 & 100.0 & 60 & 100.0 & 120 & 100.0 \\
\hline
\end{tabular}

Table 3: Distribution of Laterality

\begin{tabular}{|l|l|l|l|l|l|l|}
\hline \multirow{2}{*}{ Laterality } & \multicolumn{2}{|l|}{ Temporal incision } & \multicolumn{2}{l|}{ Superior incision } & \multicolumn{2}{l|}{ Total } \\
\cline { 2 - 7 } & No & \% & No & \% & No & \% \\
\hline Left eye & 30 & 50.0 & 32 & 53.3 & 62 & 51.7 \\
\hline Right eye & 30 & 50.0 & 28 & 46.7 & 58 & 48.3 \\
\hline Total & 60 & 100.0 & 60 & 100.0 & 120 & 100.0 \\
\hline
\end{tabular}

Table 4: Distribution of Pre-operative visual acuity

\begin{tabular}{|l|l|l|l|l|l|l|}
\hline \multirow{2}{*}{$\begin{array}{l}\text { Pre-op Visual } \\
\text { acuity }\end{array}$} & \multicolumn{2}{l|}{$\begin{array}{l}\text { Temporal incision } \\
(\mathrm{n}=60)\end{array}$} & \multicolumn{2}{l|}{$\begin{array}{l}\text { Superior incision } \\
(\mathrm{n}=60)\end{array}$} & \multicolumn{2}{l}{$\begin{array}{l}\text { Total } \\
(\mathrm{n}=120)\end{array}$} \\
\cline { 2 - 7 } & No & $\%$ & No & $\%$ & No & $\%$ \\
\hline $6 / 60$ & 20 & 33.3 & 24 & 40.0 & 44 & 36.7 \\
\hline HM CF & 2 & 3.3 & 6 & 10.0 & 8 & 6.7 \\
\hline CF (1-3mts) & 30 & 50.0 & 20 & 33.3 & 50 & 41.7 \\
\hline PL+VE & 8 & 13.3 & 10 & 16.7 & 18 & 15.0 \\
\hline
\end{tabular}

Table 5: Distribution of Pre-Operative Astigmatism in two groups

\begin{tabular}{|c|c|c|c|c|c|c|}
\hline \multirow[t]{2}{*}{$\begin{array}{l}\text { Pre-op } \\
\text { astigmatism }\end{array}$} & \multicolumn{2}{|c|}{$\begin{array}{l}\text { Temporal incision } \\
(n=60)\end{array}$} & \multicolumn{2}{|c|}{$\begin{array}{l}\text { Superior incision } \\
(n=60)\end{array}$} & \multicolumn{2}{|c|}{ Total } \\
\hline & No & $\%$ & No & $\%$ & No & $\%$ \\
\hline WTR & 20 & 33.3 & 30 & 50.0 & 50 & $41.6 \%$ \\
\hline ATR & 36 & 60.0 & 26 & 43.3 & 62 & $51.6 \%$ \\
\hline NA & 4 & 6.7 & 4 & 6.7 & 8 & $6.6 \%$ \\
\hline Total & 60 & 100.0 & 60 & 100.0 & 120 & 100.0 \\
\hline
\end{tabular}




\section{ORIGINAL ARTICLE}

Table 6: Comparison of Mean Astigmatism in patients with WTR pre-operatively

\begin{tabular}{|l|l|l|l|l|l|}
\hline WTR & $\begin{array}{l}\text { Pre } \\
\text { operative }\end{array}$ & $\begin{array}{l}\text { Post Op } \\
\text { 1st Day }\end{array}$ & $\begin{array}{l}\text { Post - Op } \\
\text { Second Week }\end{array}$ & $\begin{array}{l}\text { Post - Op } \\
\text { Fourth } \\
\text { week }\end{array}$ & $\begin{array}{l}\text { Post - Op Sixth } \\
\text { Week }\end{array}$ \\
\hline $\begin{array}{l}\text { Temporal incision } \\
\text { group (n=20) }\end{array}$ & $0.8 \pm 0.63$ & $1.38 \pm 0.96$ & $1.25 \pm 0.78$ & $1.35 \pm 0.94$ & $1.11 \pm 0.88$ \\
\hline $\begin{array}{l}\text { Superior incision } \\
\text { group (n=30) }\end{array}$ & $0.98 \pm 0.49$ & $2.25 \pm 0.83$ & $1.40 \pm 0.65$ & $1.00 \pm 0.59$ & $0.65 \pm 0.68$ \\
\hline P value & 0.425 & $0.023^{*}$ & 0.617 & 0.302 & 0.163 \\
\hline
\end{tabular}

Table 7: Comparison of Mean Astigmatism in patients with ATR Astigmatism pre-operatively

\begin{tabular}{|l|l|l|l|l|l|}
\hline ATR & Pre operative & $\begin{array}{l}\text { Post Op } \\
\text { 1st Day }\end{array}$ & $\begin{array}{l}\text { Post - Op Second } \\
\text { Week }\end{array}$ & $\begin{array}{l}\text { Post - Op Fourth } \\
\text { week }\end{array}$ & $\begin{array}{l}\text { Post - Op Sixth } \\
\text { Week }\end{array}$ \\
\hline $\begin{array}{l}\text { Temporal incision } \\
\text { group (n=36) }\end{array}$ & $0.75 \pm 0.38$ & $1.09 \pm 0.91$ & $0.75 \pm 0.74$ & $0.43 \pm 0.39$ & $0.38 \pm 0.3$ \\
\hline $\begin{array}{l}\text { Superior incision } \\
\text { group (n=24) }\end{array}$ & $0.77 \pm 0.31$ & $1.92 \pm 0.75$ & $1.07 \pm 0.44$ & $1.50 \pm 0.69$ & $1.83 \pm 0.72$ \\
\hline P value & 0.881 & $0.012^{*}$ & 0.170 & $<0.001^{* *}$ & $<0.001^{* *}$ \\
\hline
\end{tabular}

Table 8: Comparison of Astigmatism (type) in the two groups

\begin{tabular}{|c|l|l|l|l|l|l|}
\hline Astigmatism (type) & $\begin{array}{l}\text { Pre } \\
\text { operative }\end{array}$ & $\begin{array}{l}\text { Post Op 1st } \\
\text { Day }\end{array}$ & $\begin{array}{l}\text { Post - Op } \\
\text { Second } \\
\text { Week }\end{array}$ & $\begin{array}{l}\text { Post - Op } \\
\text { Fourth week }\end{array}$ & $\begin{array}{l}\text { Post - Op } \\
\text { Sixth Week }\end{array}$ & $\begin{array}{l}\text { \%hange } \\
\text { chan }\end{array}$ \\
\hline $\begin{array}{c}\text { Temporal incision } \\
\text { group(n=60) }\end{array}$ & & & & & & \\
\hline$\bullet \quad$ WTR & $20(33.3 \%)$ & $38(63.3 \%)$ & $38(63.3 \%)$ & $36(60 \%)$ & $40(66.7 \%)$ & $+33.3 \%$ \\
\hline - ATR & $36(60 \%)$ & $20(33.3 \%)$ & $20(33.3 \%)$ & $14(23.3 \%)$ & $16(26.7 \%)$ & $-33.3 \%$ \\
\hline$\bullet \quad$ NA & $4(6.7 \%)$ & $2(3.3 \%)$ & $2(3.3 \%)$ & $10(16.7 \%)$ & $4(6.7 \%)$ & - \\
\hline $\begin{array}{c}\text { Superior incision } \\
\text { group (n=60) }\end{array}$ & & & & & & \\
\hline WTR & $30(50 \%)$ & $10(16.7 \%)$ & $10(16.7 \%)$ & $10(16.7 \%)$ & $8(13.3 \%)$ & $-36.7 \%$ \\
\hline ATR & $26(43.3 \%)$ & $50(83.3 \%)$ & $50(83.3 \%)$ & $44(73.3 \%)$ & $42(70 \%)$ & $+26.7 \%$ \\
\hline NA & $4(6.7 \%)$ & $0(0 \%)$ & $0(0 \%)$ & $6(10 \%)$ & $10(16.7 \%)$ & $+10.0 \%$ \\
\hline P value & 0.432 & $<0.001 * *$ & $<0.001 * *$ & $<0.001 * *$ & $<0.001 * *$ & - \\
\hline
\end{tabular}




\section{ORIGINAL ARTICLE}

Table 9: Comparison of Mean Calculated SIA in two groups

\begin{tabular}{|l|l|l|l|}
\hline Variables & Temporal incision & Superior incision & P value \\
\hline Calculated SIA & $0.77 \pm 0.54$ & $1.38 \pm 0.51$ & $<0.001^{* *}$ \\
\hline Calculated Axis & $95.67 \pm 30.50$ & $108.80 \pm 73.28$ & 0.369 \\
\hline
\end{tabular}

Table 10: Amplitude of Astigmatism

\begin{tabular}{|l|l|l|l|}
\hline $\begin{array}{l}\text { Amplitude of } \\
\text { Astigmatism }\end{array}$ & $\begin{array}{l}\text { Temporal } \\
\text { incision group } \\
(\mathbf{n = 6 0 )}\end{array}$ & $\begin{array}{l}\text { Superior incision } \\
\text { group (n=60) }\end{array}$ & P value \\
\hline $\begin{array}{l}\text { Mean Pre-Operative } \\
\text { Amplitude }\end{array}$ & $0.72 \pm 0.50$ & $0.83 \pm 0.46$ & 0.388 \\
\hline $\begin{array}{l}\text { Mean Post-Operative } \\
\text { Amplitude }\end{array}$ & $0.87 \pm 0.64$ & $1.44 \pm 0.43$ & $<0.001^{* *}$ \\
\hline Mean SIA Amplitude & $0.77 \pm 0.54$ & $1.37 \pm 0.51$ & $<0.001^{* *}$ \\
\hline
\end{tabular}

Table 11: Centroid

\begin{tabular}{|l|l|l|}
\hline Centroid Holladay & Temporal incision group(n=60) & Superior incision group(n=60) \\
\hline Mean Pre-Operative Centroid & $0.19 \times 14$ & $0.16 \times 74$ \\
\hline Mean Post-Operative Centroid & $0.34 \times 77$ & $0.97 \times 0$ \\
\hline Mean SIA Centroid & $0.48 \times 86$ & $1.11 \times 178$ \\
\hline
\end{tabular}

Table 12: Comparison of Visual Acuity in the two group's post-operative

\begin{tabular}{|l|l|l|l|l|l|l|}
\hline Visual activity & Preoperative & $\begin{array}{l}\text { Pos0p1st } \\
\text { Day }\end{array}$ & $\begin{array}{l}\text { Post - Op } \\
\text { Second } \\
\text { Week }\end{array}$ & $\begin{array}{l}\text { Post - Op } \\
\text { Fourth } \\
\text { week }\end{array}$ & $\begin{array}{l}\text { Post -Op Sixth } \\
\text { Week }\end{array}$ & \% change \\
\hline $\begin{array}{l}\text { Temporal } \\
\text { incision } \\
\text { (n=60) }\end{array}$ & & & & & \\
\hline $6 / 6-6 / 9$ & - & $0(0 \%)$ & $8(13.3 \%)$ & $40(66.7 \%)$ & $48(80 \%)$ & $+80.0 \%$ \\
\hline $6 / 12-6 / 18$ & - & $14(23.3 \%)$ & $30(50 \%)$ & $14(23.3 \%)$ & $10(16.7 \%)$ & $+16.7 \%$ \\
\hline $6 / 24-6 / 36$ & - & $\begin{array}{l}18(30 \\
\%)\end{array}$ & $16(26.7 \%)$ & $6(10 \%)$ & $2(3.3 \%)$ & $+3.3 \%$ \\
\hline $6 / 60$ & $20(33.3 \%)$ & $26(43.3 \%)$ & $6(10 \%)$ & $0(0 \%)$ & $0(0 \%)$ & $-33.3 \%$ \\
\hline HMCF & $2(3.3 \%)$ & - & - & - & - & $-3.3 \%$ \\
\hline CFCF & $30(50 \%)$ & $2(3.3 \%)$ & - & - & - & $-50.0 \%$ \\
\hline PL+VE & $8(13.3 \%)$ & - & - & - & - & $-13.3 \%$ \\
\hline
\end{tabular}




\section{ORIGINAL ARTICLE}

\begin{tabular}{|l|l|l|l|l|l|l|}
\hline $\begin{array}{l}\text { Superior incision } \\
\text { group (n=60) }\end{array}$ & & & & & & \\
\hline $6 / 6-6 / 9$ & - & $2(3.3 \%)$ & $4(6.7 \%)$ & $10(16.7 \%)$ & $20(33.3 \%)$ & $+33.3 \%$ \\
\hline $6 / 12-6 / 18$ & - & $4(6.7 \%)$ & $18(30 \%)$ & $32(53.3 \%)$ & $34(56.7 \%)$ & $+56.7 \%$ \\
\hline $6 / 24-6 / 36$ & - & $18(30 \%)$ & $28(46.7 \%)$ & $12(20 \%)$ & $6(10.0 \%)$ & $+10.0 \%$ \\
\hline $6 / 60$ & $24(40 \%)$ & $28(46.7 \%)$ & $10(16.7 \%)$ & $6(10 \%)$ & - & $-40.0 \%$ \\
\hline HMCF & $6(10 \%)$ & - & & - & - & $-10.0 \%$ \\
\hline CFCF & $20(33.3 \%)$ & $8(13.3 \%)$ & - & - & - & $-33.3 \%$ \\
\hline PL+VE & $10(16.7 \%)$ & - & - & - & - & $-16.7 \%$ \\
\hline P value & 0.386 & 0.223 & 0.237 & $<0.001^{* *}$ & $<0.001^{* *}$ & - \\
\hline
\end{tabular}

FIGURES:

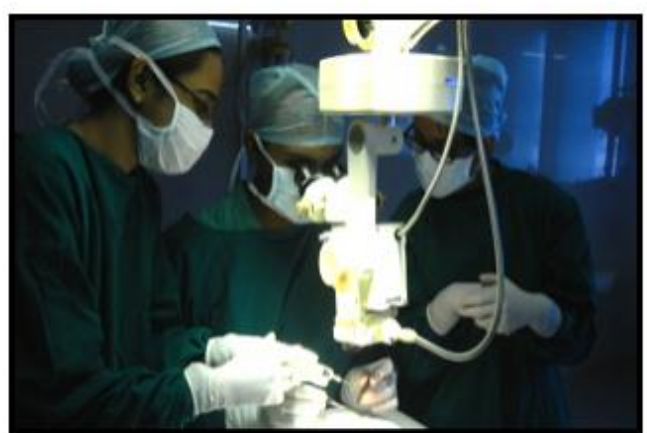

A - Position of Surgeon

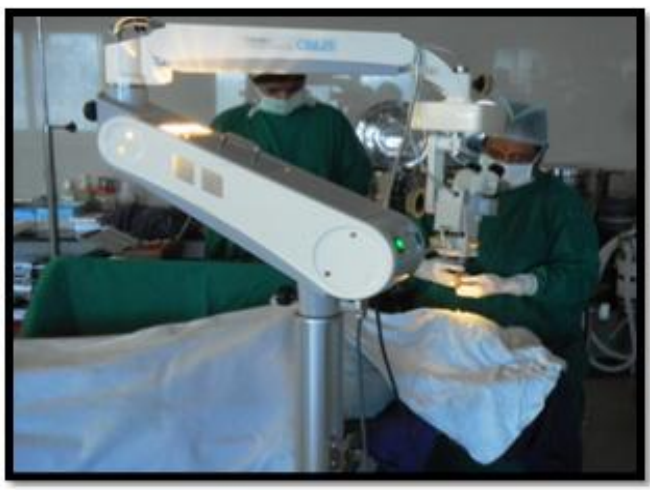

A- Position of Surgeon

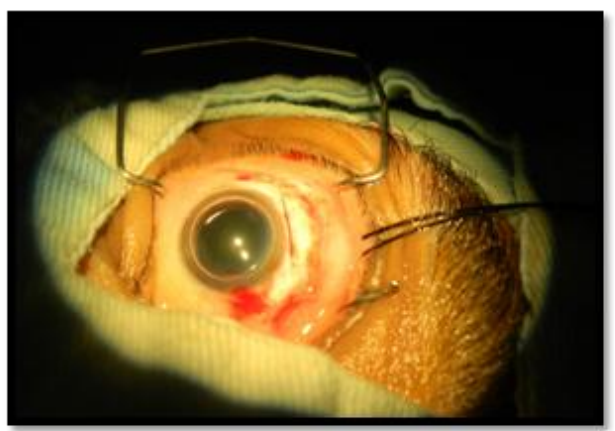

B - Superior Scleral Straight Incision

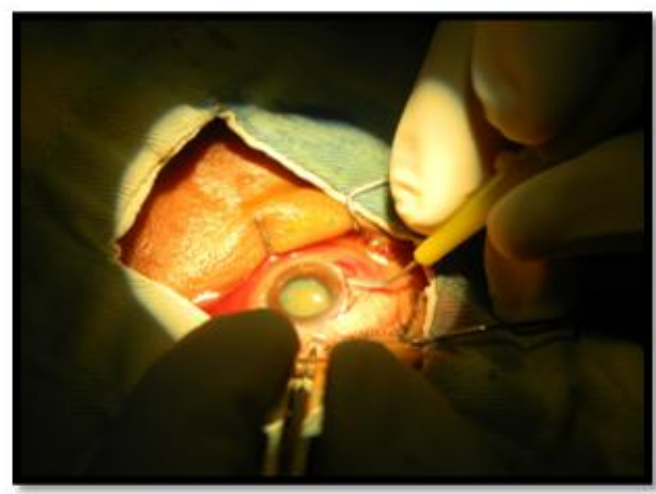

B- Temporal Scleral Straight Incision 